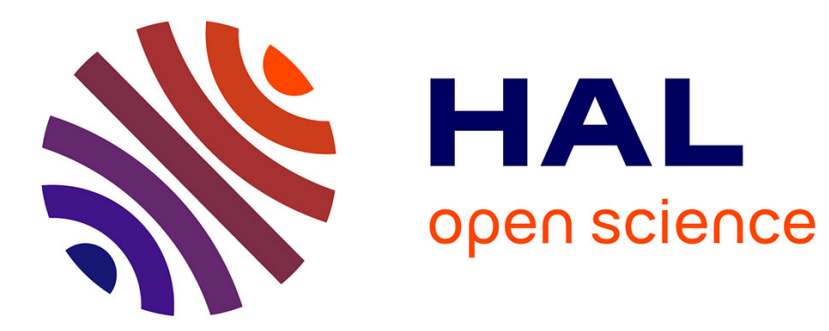

\title{
Self-Biasing Effects Induced by RF Step-Stress in Ka-Band LNAs based on InAlN/GaN HEMT Technology
}

Jean-Guy Tartarin, Séraphin Dieudonné Nsele, S Piotrowitcz, S Delage

\section{To cite this version:}

Jean-Guy Tartarin, Séraphin Dieudonné Nsele, S Piotrowitcz, S Delage. Self-Biasing Effects Induced by RF Step-Stress in Ka-Band LNAs based on InAlN/GaN HEMT Technology. 11th European Microwave Integrated Circuits Conference (EuMIC 2016), Oct 2016, Londres, United Kingdom. 10.1109/EuMIC.2016.7777596 . hal-02088210

HAL Id: hal-02088210

https://hal.laas.fr/hal-02088210

Submitted on 2 Apr 2019

HAL is a multi-disciplinary open access archive for the deposit and dissemination of scientific research documents, whether they are published or not. The documents may come from teaching and research institutions in France or abroad, or from public or private research centers.
L'archive ouverte pluridisciplinaire HAL, est destinée au dépôt et à la diffusion de documents scientifiques de niveau recherche, publiés ou non, émanant des établissements d'enseignement et de recherche français ou étrangers, des laboratoires publics ou privés. 


\section{Self-Biasing Effects Induced by RF Step-Stress in Ka-Band LNAs based on InAlN/GaN HEMT Technology}

\author{
J.G. Tartarin, S.D. Nsele \\ LAAS-CNRS and University of Toulouse (UPS) \\ F31-031, Toulouse, France \\ tartarin@laas.fr
}

\author{
S. Piotrowitcz, S. Delage \\ Thales Research Technology, III-V Lab \\ Palaiseau, France
}

\begin{abstract}
Nitride technologies are proposing a large variety of active devices to address high-power modules, but also robust low-noise receivers at high frequencies. High Electron Mobility Transistors (HEMT) are essentially developed on AlGaN/GaN heterostructure, but InAIN/GaN alternative seems very promising due to lattice matched layers (using $17 \%$ of In content) at the interface between layers where the channel (2DEG) occurs, and to a better mobility in the 2DEG. This paper presents a study on Ka-band Low Noise Amplifiers featuring a Noise Figure of 3.3 dB between $29-30.5 \mathrm{GHz}$ for the single stage version under study. RF step-stresses and CW stresses have been applied on four different LNAs, evidencing fluctuation of charges in the active device. Self-biasing of the HEMT is emphasized and assessed through the evaluation of the $2^{\text {nd }}$ order harmonic at $59 \mathrm{GHz}$. Initial noise and dynamic performances can be fully recovered after a long period with no RF signal, or by applying a positive voltage on the gate to remove charges under the gated zone of the transistor. These results on the stability of the noise figure of LNAs prove that jamming signals can be harmless on GaN based receivers, even if some more improvements have to be achieved on these not yet mature technologies.
\end{abstract}

Keywords-component; GaN HEMT, InAlN/GaN, LNA, Noise Figure, Ka-band, step-stress, CW stress.

\section{INTRODUCTION}

High power amplifiers used in wireless telecommunication or radar applications have motivated the development of wide bandgap emerging technologies. Electrical performances and thermal budgets position these technologies as a major competitor for power segment modules, through the development of solid state power amplifiers (SSPA). On the other hand, the ability of these technologies to endure high input power is also a key-point to address in robust receivers: the development of robust low noise amplifiers (LNA) represents a challenging aspect for developing high frequency, high power and low noise $\mathrm{GaN}$ technologies. If $\mathrm{AlGaN} / \mathrm{GaN}$ high electron mobility transistors (HEMT) are still suffering from a lack of reliability (some failures are attributed to lattice defects resulting from the mismatch and from the piezoelectric effects), InAIN/GaN HEMT is expected to improve the mechanical stability of the heterostructure, and thus the reliability of the transistor. Moreover, a higher output current density can lead to a higher power density if the breakdown voltage is preserved. The targeted application concerns Ka- band transceivers. Different versions of LNAs have been developed on the optimized nitride technology. In this paper, a one-stage LNA has been investigated under small-signal and large signal conditions versus RF CW and step-stresses in Kaband. In the next section, the high-frequency dynamic and noise performances of the transistor are presented. The third section presents the design and the performances of the 1-stage LNA. The last paragraph concerns the electrical behavior of the LNA versus RF input signal at $29.5 \mathrm{GHz}$ for CW and stepstresses.

\section{INALN/GAN MOS-HEMT TECHNOLOGY}

The transistors used to design the LNAs are InAlN/GaN HEMTs and MOS-HEMTs grown on 3 inches SiC substrate by using the MOCVD technique. The technological process has been optimized considering the transition frequency $f_{t}$ and maximum oscillation frequency $f_{\max }$, the output power at the $1 \mathrm{~dB}$ compression point and the HF noise figure (NF) for Kaband applications. $f_{t}=40 \mathrm{GHz}$ and $f_{\max }=110 \mathrm{GHz}$ have been achieved for the MOS-HEMT process used to design the Kaband amplifiers of this study. Power densities of $3.5 \mathrm{~W} / \mathrm{mm}$ and power added efficiencies of $40 \%$ have been measured at $30 \mathrm{GHz}$ on $0.15 \mu \mathrm{m}$ gate length devices $(6 \times 50 \mu \mathrm{m}$ gate width). The optimum low noise sizing and biasing conditions have been obtained for a $0.15 \mu \mathrm{m}$ gate length device featuring $2 \times 75 \mu \mathrm{m}$ gate width, biased at $V_{D S}=6 \mathrm{~V}$ and $I_{D S}=20 \mathrm{~mA}$; a minimum noise figure of $F_{\text {min }}=2 \mathrm{~dB}$ with an associated gain of $7.5 \mathrm{~dB}$ are measured at $30 \mathrm{GHz}$ [1].

\section{ROBUST KA-BAND LNA DESIGNS}

Different LNA versions have been designed using hybrid (MIC) and monolithic (MMIC) technologies. This paper focuses on the study developed for the one-stage hybrid LNA which allows the analysis of the single transistor contribution to the electrical performances of the LNA when subjected to RF stresses. MOS-HEMTs are flip-chipped on alumina substrate, with via holes to interconnect the ground to the metal board. The MIC circuit layout (without flip-chipped transistor) is presented in Fig. 1, and the final LNA photograph is proposed in Fig. 2. 


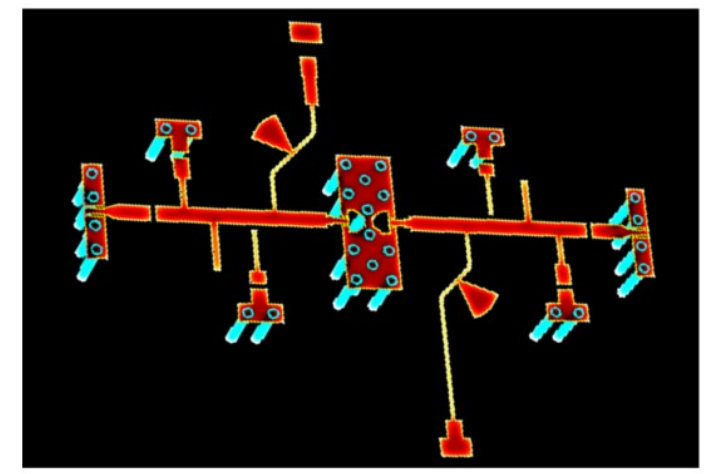

Fig. 1. Layout of the LNA (MIC with via holes and flip-chip footprint of the transistor, input and output coplanar pads for GSG probe contact).

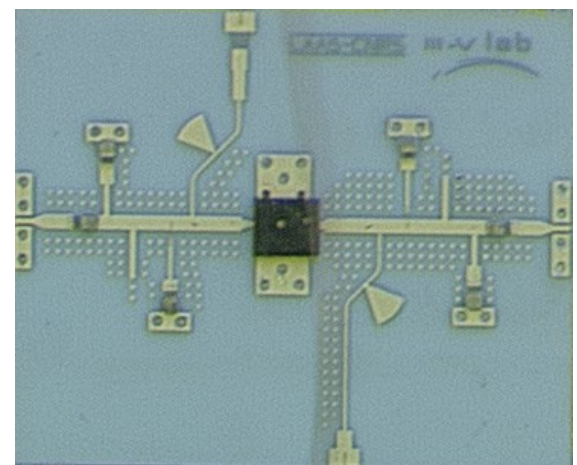

Fig. 2. Photograph of the 1-stage Ka-band LNA (flip-chipped mounted InAlN/GaN MOS-HEMT, biased at $V_{D S}=6 \mathrm{~V}, I_{D S}=20 \mathrm{~mA}$ ). Total size of the circuit is $9 \times 7.5 \mathrm{~mm}^{2}$.

Flip-chip report of the active device is convenient to reduce the transistor-to-circuit connection lengths and associated losses. Moreover, the connections by bumps can act as thermal bridges to dissipate the heat from the transistor's active zone. The small wavelength at $30 \mathrm{GHz}$ makes possible the use of distributed matching and design techniques. For this study, four different amplifiers have been assembled and characterized. Noise figures have been measured between 3.3 $\mathrm{dB}$ and $3.9 \mathrm{~dB}$ at $29.5 \mathrm{GHz}$ over the four LNAs, which is 0.3 $\mathrm{dB}$ above the simulated value. The gain measurements at 29.5 $\mathrm{GHz}$ range between $6.1 \mathrm{~dB}$ and $6.7 \mathrm{~dB}$ for three LNAs (one amplifier features a marginal $3.7 \mathrm{~dB}$ gain). The noise figure for the 1-stage LNA is reported in Fig. 3, with other works based on GaN technologies and compiled from literature [2]-[12]. Few LNAs have been designed in the Ka-band, and this work presents state of the art figure of merit with the NF measured at $3.3 \mathrm{~dB}$ (MIC 1-stage LNA), despite using a relatively immature technology.

Three stages LNAs have also been designed using the same device sizing and biasing, in MMIC technology (GH25 design kit from UMS). For these MMIC LNA designs $\left(3 \mathrm{~mm}^{2}\right)$, much more flexibility is allowed in comparison with hybrid circuits as the source contact allows fine adjustment of serial feedback since it is also possible to mix lumped elements and transmission lines. For this reason, very competitive noise figures are achieved: Noise Figures of $3 \mathrm{~dB}$ and $2.6 \mathrm{~dB}$ were simulated for the LNAs respectively using lumped and distributed lines at $30 \mathrm{GHz}$ (for small signal gain above $20 \mathrm{~dB}$ and input/output reflection coefficient lower than $-10 \mathrm{~dB}$ over 26-34 GHz) [13].

For this study, only single-stage hybrid LNAs have been tested versus $\mathrm{CW}$ and $\mathrm{RF}$ stresses at $30 \mathrm{GHz}$.

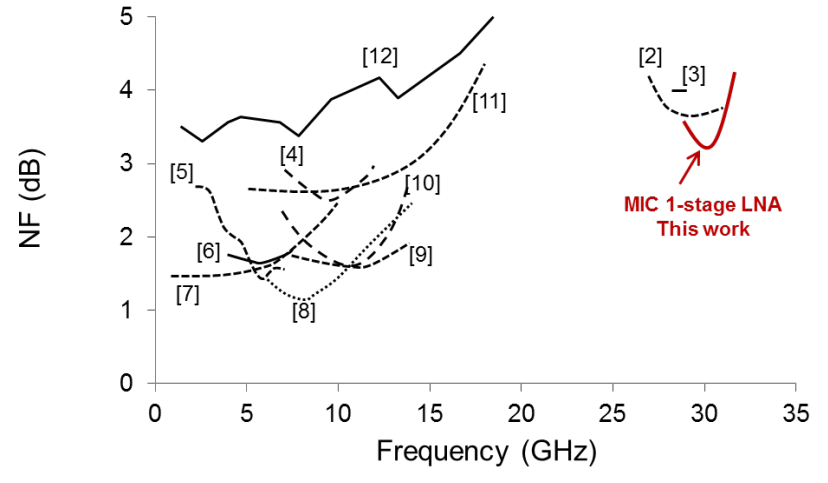

Fig. 3. State-of-the art in GaN LNA technologies. References are largely inspired from [2]. This work reports InAlN/GaN based LNA

\section{RF STRESSES IN KA-BAND}

The robustness assessment of a LNA based on III-N technologies can be developed by applying thermal stresses, $\mathrm{CW}$ stresses at several compression points, or step-stresses to evaluate the behavior of the amplifier under a harsh or critical operating environment. In this paper, RF stresses have been applied at $29.5 \mathrm{GHz}$, using an Anritsu MG3694B $40 \mathrm{GHz}$ synthesizer and a $67 \mathrm{GHz}$ Rohde \& Schwarz spectrum analyzer was used for fundamental and $2^{\text {nd }}$ harmonic power detection.

\section{A. Stress under $29.5 \mathrm{GHz} C W$ signal at $4 d B$ compression point}

After a power characterization $\left(P_{\text {out }}-P_{\text {in }}\right.$ at $29.5 \mathrm{GHz}$ featuring $P_{1 d B}=10 \mathrm{dBm}$ for the LNA reported in this study), the LNA has been stressed by a CW signal at $4 \mathrm{~dB}$ compression over 32 hours (Fig. 4 represents the first 24 hours). A rapid decrease of the DC drain current (more than $10 \%$ ) in the first 5 hours can be correlated to the reduction of $0.6 \mathrm{~dB}$ in the compressed signal of the fundamental tone. Surprisingly, the DC drain current still decreases according to a monotonous trend (quasi Neperian logarithmic law) whereas the output compressed power at $29.5 \mathrm{GHz}$ fluctuates by more than $1.5 \mathrm{~dB}$ and then remains constant at $2 \mathrm{~dB}$ under the initial gain value (no manual data collection between $10 \mathrm{~h}$ and $15 \mathrm{~h}$ in Fig. 4). From different studies in a lower frequency range, it has been proved that the InAlN/GaN MOS-HEMT is very sensitive to charges located in the gate-drain and gate-source regions (evidenced by LF noise and HF frequency dispersion on both the transconductance gain $g_{m}$ and output dynamic conductance $\left.g_{D S}\right)[14][15]$. The application of a large signal during long stress periods can activate secondary generators (self-biasing) that makes the output power fluctuate. The power-slump evidenced on this amplifier, correlated to a reduction of the carrier density in the $2 \mathrm{DEG}$, has also been 
evidenced on GaN technologies [16] and GaAs devices under large signal operation [17].

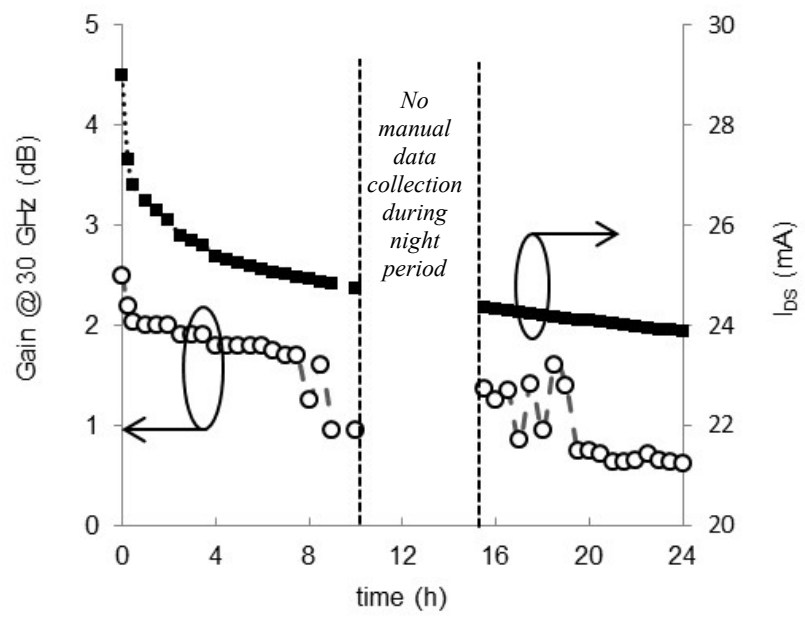

Fig. 4. Gain variation at $29.5 \mathrm{GHz}$ and DC drain current versus time for a single stage LNA under non-linear CW RF signal (@4 dB compression point).

When the RF generator is set from On to Off state, the DC drain current instantaneously shifts from $20 \mathrm{~mA}$ (initial biasing value) to $15 \mathrm{~mA}$ (Fig. 5). Then, when setting the RF signal On again, the DC current increases up to $30 \mathrm{~mA}$. From these instantaneous shifts at each cycle, $\mathrm{I}_{\mathrm{DS}}$ evolves with time. Different measurements have been performed (periods of 20 minutes for each cycle, 2 cycles for each On-Off RF signal are represented in Fig.5). This test proves that self-biasing occurs around the $20 \mathrm{~mA}$ initial DC biasing, with long recovery times involved: the evolution of $\mathrm{DC}$ biasing and $\mathrm{RF}$ signal also present a correlated general trend in Fig. 5, but RF gain fluctuations due to carriers trapped from the 2DEG also feature non-monotonous trends. Finally, more than an hour is needed to recover the initial DC drain current after RF signal shutdown. It can also be noticed that a positive gate voltage $V_{G S}=2 \mathrm{~V}$ removes instantaneously $(<1 \mathrm{sec})$ the charges under the gate and in the gate-drain region, and the initial DC quiescent point is recovered.

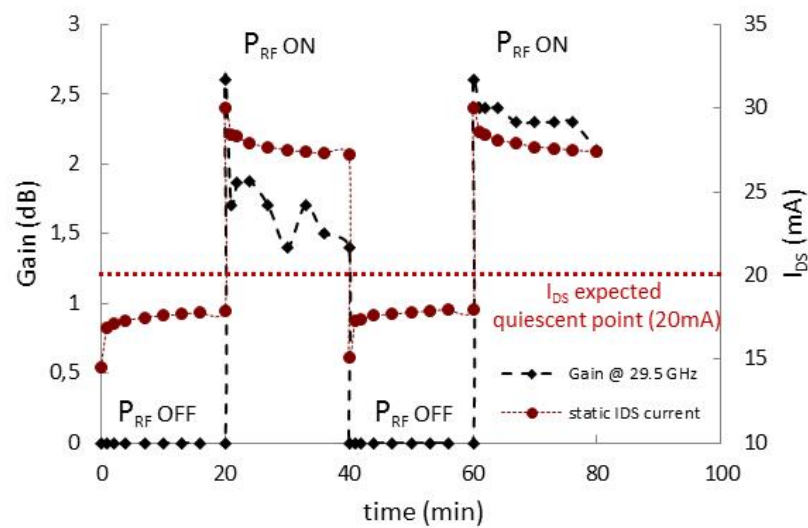

Fig. 5. Gain at $29.5 \mathrm{GHz}$ and DC drain current variations versus time for a single stage LNA under non-linear CW RF signal (@4 dB compression point). RF signal is turned $\mathrm{ON}$ and $\mathrm{OFF}$ alternately every 20 minutes.

\section{B. Step-Stress under a $29.5 \mathrm{GHz} C W$ signal}

Step stresses have been applied on two LNAs. Both were featuring a systematic change in DC drain current. For an RF input power between 10 and $14 \mathrm{dBm}$, i.e. when the transistor runs under compression, the $\mathrm{DC}$ drops down to $15 \mathrm{~mA}$ and keeps this value (same conditions as for $\mathrm{CW}$ stress under $4 \mathrm{~dB}$ compression). Several measurements have been performed to assess the validity of the measurements ( 7 iterations for each LNA). The duration of each RF step is 2 minutes, with $2 \mathrm{~dB}$ incremented RF input power. From measurements of the second harmonic power at $59 \mathrm{GHz}$ (Fig. 6), the DC selfbiasing parameter change due to RF signal application can be extracted.

The second harmonic variation law is the same as the nonlinear induced DC variation under large signal, considering the well-known linearization of $\cos ^{2}(\mathrm{x})$ given in (1), and then used to compute the quadratic function for the DC self-biasing contribution through the extraction of $b$ coefficient from (2) (limiting the polynomial expression to order 3).

$$
\cos ^{2}(\omega t)=[1+\cos (2 \omega t)] / 2
$$

$$
\mathrm{P}_{\mathrm{OUT}}=\mathrm{a} \cdot \mathrm{P}_{\mathrm{IN}}+\mathrm{b} \cdot \mathrm{P}_{\mathrm{IN}}{ }^{2}+\mathrm{c} \cdot \mathrm{P}_{\mathrm{IN}}{ }^{3}
$$

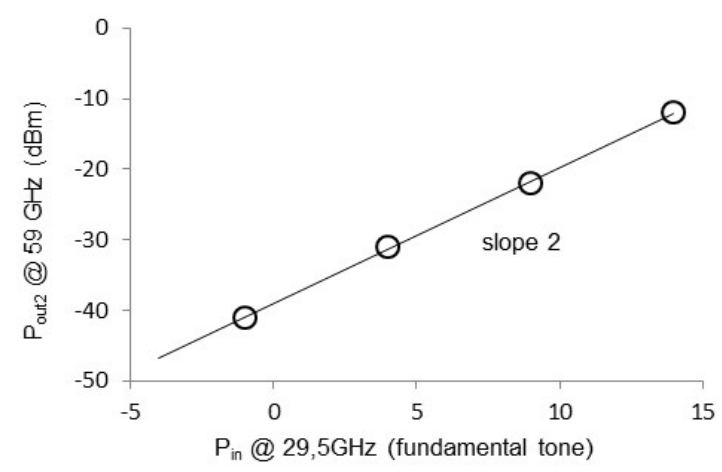

Fig. 6. Evolution of the $2^{\text {nd }}$ harmonic signal (@ $\left.59 \mathrm{GHz}\right)$ under different input power (fundamental tone @ $29.5 \mathrm{GHz}$, cf. table 1)

Since the output power for the second harmonic can be expressed by the same coefficient $b$ as for the DC self-biasing contribution, different elements given in table 1 can be computed. The RF voltage swing $\mathrm{V}_{\mathrm{GS}-\mathrm{RF}}$ on the gate is calculated from the input power $\mathrm{P}_{\mathrm{IN}}$ delivered at the matched input of the LNA, $b$ coefficient is derived from the output second harmonic P PUT2_2nd harmonic, and DC self-biasing gate voltages and drain current are estimated from the I-V loadline. The analysis of Fig. 6 leads to the extraction of $b=0.25$ for powers up to $10 \mathrm{dBm}\left(b=54\right.$ for $P_{I N}=14 \mathrm{dBm}$, which cannot be used). Table 1 reports the different electrical parameters measured $\left(P_{I N}, P_{O U T 2} \_\right.$2nd harmonic, DC measured $\left.\Delta I_{D S}\right)$ and computed ( $V_{G S-R F} @ 29.5 \mathrm{GHz}, b$ coefficient, DC self-biasing $\Delta V_{G S}$ and $\left.\Delta I_{D S}\right)$ : when using $b=0.25$ coefficient, self-biasing $\Delta V_{G S}$ and $\Delta I_{D S}$ are correctly computed for our RF 
stresses (CW and step-stress), and is also coherent with the $I_{D S}-V_{D S}$ static output characteristics of the devices. Good agreement is obtained with the measured $\Delta \mathrm{I}_{\mathrm{DS}}$ variation of the drain current of the LNA.

Finally, after several RF tests (more than 10 step-stresses and $\mathrm{CW}$ stresses), is has been evidenced that no degradation is noticeable on the small-signal gain, on $P_{1 d B}$ or on the noise figure after the transistors have recovered their initial quiescent biasing point. No permanent degradation has been evidenced during these stresses. It can be noticed that DC conditions are low voltage and low current to match low noise requirements; thus no DC stress occurs in the active devices, contrary to tests performed at high DC power for large-signal applications.

\section{TABLE I}

SELF-BIASING EFFECT DUE TO LARGE-SIGNAL RF POWER

\begin{tabular}{|c|c|c|c|c|}
\hline$P_{I N}(29.5 \mathrm{GHz})$ & $-1 \mathrm{dBm}$ & $+4 \mathrm{dBm}$ & $+9 \mathrm{dBm}$ & $+14 \mathrm{dBm}$ \\
\hline$V_{G S-R F} @ 29.5 \mathrm{GHz}$ & $0.282 \mathrm{~V}$ & $0.5 \mathrm{~V}$ & $0.9 \mathrm{~V}$ & $1.6 \mathrm{~V}$ \\
\hline POUT2_2nd harmonic & $-41 \mathrm{dBm}$ & $-31 \mathrm{dBm}$ & $-22 \mathrm{dBm}$ & $-17.5 \mathrm{dBm}$ \\
\hline$b$ coefficient & 0.25 & 0.256 & 0.21 & (using 0.25 ) \\
\hline DC self-biasing $\Delta V_{G S}$ & $0.003 \mathrm{~V}$ & $0.009 \mathrm{~V}$ & $0.025 \mathrm{~V}$ & $0.33 \mathrm{~V}$ \\
\hline DC computed $\Delta I_{D S}$ & $0 \mathrm{~mA}(0 \%)$ & $1 \mathrm{~mA}(7 \%)$ & $5 \mathrm{~mA}(33 \%)$ & $13 \mathrm{~mA}(90 \%)$ \\
\hline DC measured $\Delta I_{D S}$ & $0 \mathrm{~mA}$ & $0.7 \mathrm{~mA}$ & $6 \mathrm{~mA}$ & $15 \mathrm{~mA}$ \\
\hline
\end{tabular}

\section{CONCLUSION}

Ka-band LNAs using InAlN/GaN (MOS-)HEMT devices have been characterized at $29.5 \mathrm{GHz}$, featuring a state of the art noise figure of $\mathrm{NF}=3.3 \mathrm{~dB}$. Radio frequency $\mathrm{CW}$ stresses have been performed on different LNAs, evidencing selfbiasing effects due to the activation of charges in the gated zone of the transistor under large-signal conditions; very long recovery time constants are evidenced. A simple intuitive model has been developed to account for the self-biasing effect occurring in active devices, which matches the different RF $\mathrm{CW}$ and step stresses experiments performed on amplifiers. Finally, after those RF stresses, once the DC initial conditions are recovered, no degradation is noticed in the gain, in the compression point or in the noise figure of the low-noise amplifiers under test.

\section{ACKNOWLEDGMENT}

This work was partially supported by the Genghis Khan Project in the Framework of the French Research National Agency. The authors also acknowledge all the other partners of the project (Thales Communication, EGIDE, United Monolithic Semiconductors and Institut Lavoisier) for fruitful exchanges and discussion, and Professor L. Escotte from LAAS-CNRS for his active contribution to the characterization of HF noise parameters and transistor's modelling.

\section{REFERENCES}

[1] S.D. Nsele, J.G. Tartarin, L. Escotte, S. Piotrowicz, S. Delage, " InAIN/GaN HEMT Technology for Robust HF Receivers: an Overview of the HF and LF Noise Performances " International Conference on Noise and Fluctuation, ICNF 2015, X'Ian, China,4 p.
[2] M. Rudolph, N. Chaturvedi, K. Hirche, J. Würfl, W. Heinrich, G. Tränkle, "Highly rugged $30 \mathrm{GHz}$ GaN low-noise amplifiers," IEEE Microwave and Wireless Components Lett., vol. 19, no. 4, pp. 251-253, 2009.

[3] E.M. Suijker, J.A. Hoogland, M. Van Heijningen, M. Seelman-Eggebert, R. Quay, P. Bruckner, F.E. Van Vliet, "Robust AlGaN/GaN Low Noise Amplifier MMICs for C-, Ku- and Ka-band space applications," IEEE Compound Semiconductor Integrated Circuit Symposium, 2009. CISC 2009. 4p.

[4] M. Micovic, A. Kurdoghlian, H.P. Moyer, P. Hashimoto, A. Smitz, I. Milosavljevic, P.J. Willadsen, W.S. Wong, J. Duvall, M. Hu, M. Wetzel, D.H. Chow, "GaN MMIC technology for microwave and millimeterwave applications" in Proc. IEEE Compound Semiconductor Int. Circuits Symp. CSIC, 2005, pp. 173-176.

[5] M. Rudolph, R. Behtash, K. Hirche, J. Wurfl, W. Heinrich, G. Trankle, "A high survivable 3-7 GHz GaN Low-Noise Amplifiers," IEEE MTT-S Int. Dig., 2006, pp. 1899-1902.

[6] H. Xu, C. Sanabria, A. Chini, S. Keller, U.K. Mishra, R.A. York, "A Cband high-dynamic range GaN HEMT low-noise amplifier," IEEE Microwave Wireless Component Letters, Vol. 14, no.6, pp.262-264, June 2004.

[7] M.V. Aust, A.K Sharma, Y.C Chen, M. Wojtowicz, "Wide-band dualgate GaN HEMT low noise amplifier front-end receiver electronics," in Proc. IEEE Compound Semiconductor Int. Circuits Symp. CSIC, 2006, pp. $89-92$

[8] J.C. De Jaeger, S.L. Delage, G. Dambrine, M.A. Di Forte Poisson, V. Hoel, S. Lepilliet, B. Grimbert, E. Morvan, Y. Mancuso, G. Gauthier, A. Lefrançois, Y. Cordier, "Noise assessment of AlGaN/GaN HEMTs on Si or SiC substrates: application to X-band low noise amplifiers," in Proc. European Gallium Arsenide Other Semiconductors Appl. Symp. 2005, pp. 229-232.

[9] D. Krausse, R. Quay, R. Kiefer, A. Tessman, H. Massler, A. Leuther, T. Merkle, S. Muller, C. Schworer, M. Mikulla, M. Schlechtweg, G. Weiman, "Robust GaN HEMT low-noise amplifier MMICs for X-band applications," in Proc. European Gallium Arsenide Other Semiconductors Appl. Symp. 2004, pp. 71-74.

[10] R.S. Schwindt, V. Kumar, O. Aktas, J.W. Lee, I. Adesida, "Temperature-dependence of a GaN-based HEMT monolithic X-band low-noise amplifier," in Proc. IEEE Compound Semiconductor Int. Circuits Symp. CSIC, 2004, pp. 201-204.

[11] G.A. Ellis, J.S. Moon, D. Wong, M. Micovic, A. Kurdoghlian, P. Hashimoto, M. Hu, "Wideband AlGaN/GaN HEMT MMIC low noise amplifier," in IEEE MTT-S Int. Digest, 2004, pp.153-156.

[12] S. Colangeli, A. Bentini, W. Ciccognani, E. Limiti, A. Nanni, "GaNbased robust Low-Noise Amplifiers" IEEE Trans. On Electron Devices, Vol.60, no.10, October 2013, pp. 3238-3247.Ketterson, E.Beam, M. Pilla, X. Gao, "InAlN barrier scaled devices for very high $\mathrm{f}_{\mathrm{T}}$ and lowvoltage RF applications," IEEE Trans. Electron Devices, vol. 60, no. 10, pp. 3099-3104, 2013.

[13] S. Nsele, C. Robin, J.G. Tartarin, L. Escotte, O. Jardel, S. Piotrowitcz, S. Delage,"Ka-band Low Noise Amplifiers based on InAlN/GaN technologies", International Conference on Noise and Fluctuation, ICNF 2015, X'Ian, China, 4 p.

[14] S. Nsele, L. Escotte, J.G. Tartarin, S. Piotrowicz, S.Delage. "BroadBand Frequency Dispersion Modeling of the Output Conductance and Transconductance in AlInN/GaN HEMTs", IEEE Transactions on Electron Devices, April 2013, Vol. 60 , , pp.1372-1378

[15] S. Nsele, L. Escotte, J.G. Tartarin, S. Piotrowicz, S.Delage. "Lowfrequency noise in reverse-biased Schottky barriers on InAIN/AIN/GaN heterostructures", Applied Physics Letters, Vol.105, N¹9, 192105p., Novembre 2014.

[16] J.G. Tartarin, Invited paper "Diagnostic tools for accurate reliability investigations of GaN devices", International Conference on Noise and Fluctuations (ICNF 2011), IEEE conf., pp.456-461.

[17] T. Hisaka, Y. Nogami, H. Sasaki, A. Hasuike, N. Yoshida, K. Hayashi, T. Sonoda, A. Villanueva, J. Del Alamo, "Degradation mechanism of PHEMT under large signal operation", IEEE GaAs Symposium, $25^{\text {th }}$ annual technical Digest 2003, $4 p$. 